\title{
Removal of fermentation inhibitors from pre-hydrolysis liquor using polystyrene divinylbenzene resin
}

\author{
Caoxing Huang \\ Nanjing Forestry University \\ Yayue Zheng \\ Nanjing Forestry University \\ Wenqian Lin \\ Nanjing Forestry University \\ Yuxuan Shi \\ Nanjing Forestry University \\ Guohong Huang \\ Nanjing Hydraulic Research Institute \\ Qiang Yong ( $\square$ swhx@njfu.com.cn ) \\ Nanjing Forestry University
}

\section{Research}

Keywords: pre-hydrolysis liquor, polystyrene divinylbenzene, inhibitors, fermentability, bioconversion

Posted Date: November 6th, 2020

DOI: https://doi.org/10.21203/rs.3.rs-70189/v2

License: @ (1) This work is licensed under a Creative Commons Attribution 4.0 International License. Read Full License

Version of Record: A version of this preprint was published on November 12th, 2020. See the published version at https://doi.org/10.1186/s13068-020-01828-3. 


\section{Abstract}

Background: The presence of soluble lignin, furfural and hydroxymethylfurfural (HMF) in industrial pre-hydrolysis liquor (PHL) from the pulping process can inhibit its bioconversion into bioethanol and other biochemicals. Although various technologies have been developed to remove these inhibitors, certain amounts of sugars are also inevitably removed during the treatment process. Hence, polystyrene divinylbenzene (PS-DVB) resin was used as an adsorptive material to simultaneously remove fermentation inhibitors while retaining sugars with high yields to improve the fermentability of PHL after acid-hydrolysis by enriching its xylose concentration. The fermentability of acid-hydrolyzed PHL (A-PHL) was evaluated by the bioconversion into ethanol and xylosic acid (XA) after treatment with PS-DVB resin.

Results: The results showed that the highest xylose concentration $(101.1 \mathrm{~g} / \mathrm{L})$ in PHL could be obtained by acid-hydrolysis at $100{ }^{\circ} \mathrm{C}$ for 80 min with $4 \%$ acid, while the concentration of fermentation inhibitors (furfural, HMF and lignin) in PHL could also be significantly improved during the acid-hydrolysis process. After treatment with PS-DVB resin, not only were $97 \%$ of lignin, $92 \%$ of furfural, and $97 \%$ of HMF removed from A-PHL, but also $96 \%$ of xylose was retained for subsequent fermentation. With resin treatment, the fermentability of A-PHL could be improved by $162-282 \%$ for ethanol production from A-PHL containing $30-50 \mathrm{~g} / \mathrm{L}$ xylose and by $18-828 \%$ for XA production from A-PHL containing 90-150 g/L xylose.

Conclusions: These results confirmed that PS-DVB resin can remove inhibitors from PHL before producing value-added products by bioconversion. In addition, this work will ideally provide a concept for producing value-added chemicals from pre-hydrolysis liquor, which is regarded as the waste stream in the pulping process.

\section{Background}

Pre-hydrolysis is a necessary first step in kraft-based dissolving pulp production at pulp and/or paper mills [1,2]. Steam or hot water is used as medium to treat wood chips during the pre-hydrolysis process, which acts to hydrolyze the majority of hemicellulose and a portion of lignin from the cell wall into a prehydrolysis liquor (PHL) stream. Carbohydrates, furfurals and lignin fragments in PHL exist in the forms of solutes, particulates, and colloids, and PHL is typically regarded as a waste stream [3-4]. Currently, this liquor is just regarded as the wastewater, which is mixed with the black liquor and introduced into the recovery boiler for energy generation [5]. However, the dissolved hemicellulose in PHL only possesses a heat value of $7400 \mathrm{BTU} / \mathrm{b}$, which is significantly lower than that of the lignins that dominate black liquor (11,300 BTU/b for softwood, 10,600 BTU/b for hardwood) [6,7]. This means that the current strategy for disposing of PHL actually reduces the energy efficiency of kraft pulping operations. Because the produced PHL contains various amounts of monomeric and oligomeric sugars, as well as soluble lignin, it is possible to envision the use of this waste stream to generate high value. This strategy is in line with the overall biorefinery concept, where multiple value-added products are generated from lignocellulosic materials by different processes [8-10].

Xylose is an important industrial commodity chemical that can be used to produce xylitol, a valuable chemical to both the pharmaceutical and food industries [11]. In the biorefinery concept, xylose can be sustainably used to produce bioethanol by fermentation, which is currently obtained from starch-based crops. Developing bioethanol has been regarded as one of the approaches towards reducing $\mathrm{CO}_{2}$ emissions from fossil fuel consumption [12]. Recently, xylonic acid (XA), one of the top 30 high-value chemicals in National Renewable Energy Laboratory (NREL) and Pacific Northwest National Laboratory (PNNL) reports, can also be produced from xylose by chemical, electrochemical, or fermentative methods $[13,14]$. Due to the potential applications and great demand for xylose, various types of biomass have been explored at different scales for producing xylose via an acid hydrolysis process [15-16]. As can be expected, the technologies used for acid hydrolysis processes require carefully orchestrated plans for funding and maintenance during construction, operation, and management [17]. Considering the current industrial presence of xylose in PHL, efforts should also be carried out to upgrade the stream into value-added sustainable chemicals (as opposed to burning it). Such an approach will open an opportunity for producing biochemicals from wastewater in most existing pulp mills that conduct pre-hydrolysis processes.

During prehydrolysis, a small portion of lignin can be depolymerized into water soluble oligomers. Jiang et al. (2020) [18] found that the extensive lignin degradation occurs during prehydrolysis by homolytic cleavage of aryl-ether bonds, resulting in PHL containing abundant of aromatic compounds in the form of vanillin and syringaldehyde. Furfural and hydroxymethylfurfural (HMF) also exist in PHL due to monosaccharide dehydration during prehydrolysis [19-21]. All these aforementioned monosaccharide byproducts are regarded as fermentation inhibitors for the microbial production of bioethanol, XA, and other biochemicals [22-23]. Therefore, to efficiently utilize the xylose present in PHL, these inhibitors should be removed from PHL to improve the fermentability and xylose consumption efficiency. 
Various methods have been explored for removing inhibitors from PHL. For example, acidification has been used to treat the PHL, however only $3.8 \%$ of the soluble lignin was rendered as a filterable precipitate [24]. Wang et al. (2015) [25] used membrane filtration with different molecular mass cutoffs to treat PHL and found that the method had limited purifying ability due to overlapping between molecular weight distributions in the carbohydrate fractions. The addition of polydiallyldimethylammonium chloride (p-DADMAC) and cationic polyacrylamide (CPAM) polymers to PHL has also been carried out to flocculate the lignin and lignin-derived products [25]. Yasarla and Ramarao (2012) [26] found that flocculating agents with trivalent cations resulted in a $40 \%$ loss of sugar despite achieving $70 \%$ lignin removal. An adsorption concept using lime mud and activated carbon has also been employed to remove inhibitors in PHL. However, these approaches still cause considerably undesirable sugar adsorption/loss ( 15-20\%). Each of the aforementioned techniques is unable to simultaneously remove solubilized lignin and lignin-derived phenolic substances without hampering the recovery of sugars due to their similar molecular weight distribution and water solubility in PHL.

Differences in polarity between sugars (hydrophilic) and solubilized lignin (hydrophobic) could be exploited to more selectively fractionate inhibitors from target monosaccharides [18]. An approach for selective adsorption using porous resins comprised of materials whose chemical structures favors interaction with fermentation inhibitors can ideally be proposed. Research already exists related to lignin-selective adsorptive resins, specifically polystyrene divinylbenzene (PS-DVB) resin [27]. It has been reported that this resin possesses the ability to effectively adsorb soluble lignin and carbohydrate dehydration products while retaining most of the carbohydrate in biomass hydrolyzates due to its hydrophobic polymeric particles that can selectively adsorb similarly hydrophobic solutes through $\pi-\pi^{\prime}$ and van der Waal interactions $[27,28]$. Different from the aforementioned separation methods, the adsorbed lignin in the resin can be desorbed and potentially processed for further application. In most published works, PS-DVB resin was only used to purify biomass hydrolyzate to obtain lignin for further applying or to obtain purified lignin and lignin-carbohydrate complexes for structural analysis $[18,27,29,30]$. Few studies have used PS-DVB resin as a purification technology to remove the soluble lignin and carbohydrate dehydration products in PHL to improve its fermentability for ethanol and XA production. Hence, it is speculated that PSDVB resin could be an ideal adsorptive material to simultaneously separate lignin-derived substances and sugars with great efficiency while still improving the fermentability of PHL.

In the present work, acid treatments under different conditions were carried out to hydrolyze PHL xylooligosaccharides into xylose to maximize the quantity of available fermentation substrate. Next, a PS-DVB resin adsorption protocol with different feed flow rates was applied to remove soluble lignin, furfural and HMF. The efficiency and selectivity of this process were verified by compositional analysis of each stream and nuclear magnetic resonance (NMR) characterization. Furthermore, original A-PHL and resin-treated A-PHL with different concentrations were used to produce ethanol and XA in order to evaluate the effects of PS-DVB adsorption on the fermentability of A-PHL. This work will ideally provide a concept to produce value-added chemicals from pre-hydrolysis liquor, which is regarded as the waste stream in the pulping process.

\section{Results And Discussion}

\section{Composition analysis of the PHL}

Pre-hydrolysis is the primary technology used for kraft-based dissolving pulp production. During the pre-hydrolysis stage, most hemicellulose and portion of lignin can be removed,which are depended upon both treatments conditions for different woody feedstocks $[19,25]$. In consideration of these variables, it is necessary to obtain a detailed chemical composition of the mixed hardwood PHL used in this work. The chemical compositions of PHL are shown in Table 1. It can be seen that xylose $(86.3 \mathrm{~g} / \mathrm{L})$ and xylooligosaccharide $(32.3 \mathrm{~g} / \mathrm{L})$ are the major sugars in this PHL. In addition, a certain amount of glucose $(7.5 \mathrm{~g} / \mathrm{L})$, arabinose $(6.1 \mathrm{~g} / \mathrm{L})$ and sugar-derived byproducts $(0.9 \mathrm{~g} / \mathrm{L}$ of furfural and $0.4 \mathrm{~g} / \mathrm{L}$ of HMF) were quantified. The high concentration of xylooligosaccharides in PHL confirms that this stream can be further transformed into xylose-rich solution by hydrolyzing xylooligosaccharides into xylose. The sugar contents in this PHL were significantly higher than those in the PHL (40-60 g/L) used in the work of Shi et al., (2012) [3]. This difference occurred because the used mixed hardwood PHL was obtained after steam concentration. In addition, it is important to note that a high concentration $(42.1 \mathrm{~g} / \mathrm{L})$ of soluble lignin also existed in the PHL.

Table 1 Composition analysis of PHL, A-PHL, and P-A-PHL (g/L) 


\begin{tabular}{llll}
\hline & PHL $^{a}$ & A-PHL $^{b}$ & P-A-PHL $^{c}$ \\
\hline Xylose & $86.3 \pm 0.3$ & $101.1 \pm 1.1$ & $97.1 \pm 0.9$ \\
Glucose & $7.5 \pm 1.2$ & $8.8 \pm 0.3$ & $8.4 \pm 0.1$ \\
Arabinose & $6.1 \pm 0.2$ & $4.5 \pm 0.2$ & $4.3 \pm 0.5$ \\
HMF & $0.4 \pm 0.2$ & $1.9 \pm 0.1$ & $0.04 \pm 0.01$ \\
Furfural & $0.9 \pm 0.4$ & $7.8 \pm 1.2$ & $0.6 \pm 0.1$ \\
Xylooligosaccharide & $32.3 \pm 2.1$ & $/$ & $/$ \\
Glucooligosaccharides & $3.3 \pm 1.1$ & $/$ & $/$ \\
Soluble lignin & $42.1 \pm 0.5$ & $42.9 \pm 0.6$ & $2.1 \pm 0.3$ \\
\hline
\end{tabular}

a: pre-hydrolysis liquor

b: PHL after acid-hydrolysis

C: A-PHL after purification by PS-DVB resin

Two-dimensional heteronuclear single-quantum coherence (2D-HSQC) NMR, an advanced technology that has been used to characterize samples with carbohydrate and lignin mixtures [31] or lignin-carbohydrate complexes [32], was carried out to understand the structural information of the chemical components in the PHL. The obtained spectra are shown in Fig. 1(a). Peaks in the 2D-HSQC spectra are assigned according to recent works [33,34].

The signals for internal xylan units $(X)$ were clear and obvious in the spectra. Specifically, the $\mathrm{C}_{2} / \mathrm{H}_{2}, \mathrm{C}_{3} / \mathrm{H}_{3}, \mathrm{C}_{4} / \mathrm{H}_{4}$, and $\mathrm{C}_{5} / \mathrm{H}_{5}$ positions showed correlation signals at 72.3/3.03,73.9/3.22, 75.3/3.48, and 62.9/3.15, 3.85 ppm, respectively. In addition, xylan with reducing-end units $\left(X_{R}\right)$ was also identified from the $\mathrm{C}_{2} / \mathrm{H}_{2}$ and $\mathrm{C}_{4} / \mathrm{H}_{4}$ correlation signals at $74.4 / 2.89$ and $75.3 / 3.48 \mathrm{ppm}$, respectively. The presence of $X_{R}$ indicates that the soluble xylan (xylo-oligosaccharide) in the PHL possesses a relatively low degree of polymerization, which makes it a promising resource for xylose production [31].

In addition, the spectra of PHL showed common lignin substructures of $\beta-0-4(A), \beta-\beta(B)$, and $\beta-5(C)$, which can be identified by their $C_{a^{-}}$ $\mathrm{H}_{a}$ signals at $71.8 / 4.86,84.9 / 4.69$, and $86.8 / 5.49 \mathrm{ppm}$, respectively. Correlation signals for syringyl units (S) and guaiacyl units (G) were also noted from their $\mathrm{C}_{2}-\mathrm{H}_{2}$ and $\mathrm{C}_{2,6}-\mathrm{H}_{2,6}$ positions at $111.0 / 7.01$ and $104.1 / 6.74 \mathrm{ppm}$, respectively. Hence, it can verify the lignin fraction was present in the $\mathrm{PHL}$, which is in accordance with the results of the composition analysis.

\section{Acid hydrolysis of the PHL}

In previous work, it was reported that even though PS-DVB resin shows a low affinity for carbohydrates, some of high molecular weight carbohydrate linked to lignin can still be adsorbed by the resin [27, 29-30]. To reduce the loss of sugars in PHL and maximize the quantity of available fermentation substrate, the oligosaccharides in PHL were hydrolyzed into monosaccharides. Acid hydrolysis was carried out with sulfuric acid under different reaction conditions (acid concentration, time, and temperature) to obtain a recipe for maximizing xylooligosaccharide conversion into xylose.

The increase in xylose concentration in the PHL under different acid concentrations (1-5\%) at $100{ }^{\circ} \mathrm{C}$ for 60 min is shown in Fig. 2a. First, increasing xylose concentrations were found with increasing acid catalyst concentrations. For example, the concentration of xylose in $\mathrm{PHL}$ increased from $86.1 \mathrm{~g} / \mathrm{mL}$ to $95.4 \mathrm{~g} / \mathrm{L}$ when the acid concentration was increased from $1 \%$ to $4 \%$. However, a maximum was noted, as the xylose concentration decreased to $88.9 \mathrm{~g} / \mathrm{L}$ when the acid concentration was further increased to $5 \%$. This can be explained by the mechanism that xylose is easily dehydrated into furfural at higher acid concentration. As observed by Yang et al., (2012) [35], increasing the acid catalyst (formic acid) concentration from $5-10 \mathrm{~g} / \mathrm{L}$ could effectively dehydrate xylose into furfural, with the yield rising from 15.8 $\%$ to $74 \%$, indicating that xylose can be degraded with increasing acid concentration. Depending on the maximum xylose concentration in A-PHL, it can be speculated that $4 \%$ sulfuric acid was the optimum condition to produce the xylose from PHL.

According to the aforementioned results, the effects of different reaction temperature $\left(90-130^{\circ} \mathrm{C}\right)$ with $4 \%$ acid and 60 min of acid hydrolysis on increases in xylose concentration in PHL were investigated and are shown in Fig. $\mathbf{2 b}$. The maximum concentration of xylose in A-PHL was $95.4 \mathrm{~g} / \mathrm{L}$ at $100^{\circ} \mathrm{C}$. Increasing the reaction temperature from $100^{\circ} \mathrm{C}$ to $130{ }^{\circ} \mathrm{C}$ significantly reduced the xylose 
concentrations from $95.4 \mathrm{~g} / \mathrm{L}$ to $75.1 \mathrm{~g} / \mathrm{L}$. This result occurred because increasing the reaction temperature further accelerated the dehydration of xylose into furfural given the high acid dosage applied in this series of experiments [35]. Chen et al., (2018) [31] also found that the xylose in PHL could be further degraded under reaction temperatures from $120^{\circ} \mathrm{C}$ to $135^{\circ} \mathrm{C}$ with $4 \%$ aqueous sulfuric acid for $30 \mathrm{~min}$. Based on the maximum xylose concentration in A-PHL, it can be speculated that acid hydrolysis with a $4 \%$ acid concentration at $100^{\circ} \mathrm{C}$ was the optimum condition to produce the xylose from PHL.

The effect of the reaction time (20-100 min) of acid hydrolysis with $4 \%$ acid at $100{ }^{\circ} \mathrm{C}$ on xylose concentration in PHL is illustrated in Fig. 2c. It can be observed that the xylose concentration in the A-PHL increased first and then decreased with increasing reaction time from $20 \mathrm{~min}$ to $100 \mathrm{~min}$. The optimal reaction temperature was $80 \mathrm{~min}$, and a maximum xylose concentration of $101.1 \mathrm{~g} / \mathrm{L}$ was obtained. Therefore, the highest xylose concentration in A-PHL (with a 17\% increase relative to that of the original PHL) was obtained by acid hydrolysis at $100^{\circ} \mathrm{C}$ for 80 min with $4 \%$ sulfuric acid dosage. These conditions approach to those of the work of Chen et al., (2018) [31], who found that an optimal xylose yield $(30.10 \mathrm{~g} / \mathrm{L})$ from poplar PHL was obtained at $120^{\circ} \mathrm{C}$ for $0.5 \mathrm{~h}$ with $4 \%$ aqueous sulfuric acid.

Although a higher xylose concentration can be obtained in PHL by applying acid hydrolysis, this method has also been shown to unavoidable lead to the dehydration of sugars (xylose and glucose) into fermentation inhibitors (furfural and HMF). As seen in Table 1, the PHL subjected to acid treatment under (A-PHL) the aforementioned optimal condition contained a higher xylose concentration than the original PHL. However, the concentration of furfural and HMF were $7.8 \mathrm{~g} / \mathrm{L}$ and $1.9 \mathrm{~g} / \mathrm{L}$, respectively. These quantities are significantly higher than those in PHL (0.9 g/L and $0.4 \mathrm{~g} / \mathrm{L})$. In the reported work of Bellido et al (2011) [36], it was found that the pentose-fermenting yeast $P$. stipitis had poor tolerance towards furfural and HMF, with cell growth almost completely inhibited when the fermentation media contained at least $2 \mathrm{~g} / \mathrm{L}$ furfural. In addition, various phenolic compounds formed from the degradation of lignin can inhibit the efficiency of ethanol fermentation. Zhou et al., (2017) [37] found a significant inhibitory effect of furfural occurred using a $G$. oxydans fermentation system with prehydrolyzate containing $6.5 \mathrm{~g} / \mathrm{L}$ furfural, revealing the toxicity of furfural for XA production from $G$. oxydans. In addition, the concentration of water soluble lignin $(44.9 \mathrm{~g} / \mathrm{L})$ was slightly increased in A-PHL relative to that in PHL. As pointed out by Wang and Chen (2011) [38], the high concentration (>2 g/L ) of lignin fractions in the sugar solutions can also cause an inhibitory effect on fermentation. Thus, removing the fermentation inhibitors in A-PHL not only provides a favorable environment for pentose-fermenting yeast but also removes a critical hurdle towards the fermentation of xylose to XA by G. oxydans.

\section{Purification of PHL by PS-DVB resin}

Lignin and sugar-derived byproducts in PHL are difficult to separate from sugars due to their similar molecular weights and water solubilities [27]. In this work, we used a lignin-selective adsorptive resin to separate the lignin and sugar byproducts (furfural and HMF) from A-PHL while retaining most of the sugars in the A-PHL. A diagram of the process used is shown in Fig. 3. The lignin and sugar byproducts in A-PHL can be adsorbed in the resin, while the purified sugar solution proceeds to the next unit operation. Ethanol can be used to regenerate the resin by desorbing the adsorbates and can also be recycled to prepare lignin-based materials. Importantly, the regenerated resin can be reused in another purification process to adsorb the lignin and sugar byproducts in A-PHL. Hence, the present concept for the purification of A-PHL by PS-DVB resin is inherently environmentally friendly and sustainable.

First, the most important parameter for resin separation technology, the feed flow rate, was optimized at $0.5-4 \mathrm{~mL} / \mathrm{min}$ for the column $(40 \times 2 \mathrm{~cm})$ with a solution loading of $500 \mathrm{~mL}$ for adsorption. As shown in Table $\mathrm{S} 1$, the resin's ability to remove fermentation inhibitors (soluble lignin, furfural and HMF) was similar with an increase in flow rate from $0.5 \mathrm{~mL} / \mathrm{min}$ to $2 \mathrm{~mL} / \mathrm{min}$. However, increasing the flow rate from $2 \mathrm{~mL} / \mathrm{min}$ to $4 \mathrm{~mL} / \mathrm{min}$ resulted in a decreased removal efficiency for fermentation inhibitors, even though there was no obvious decrease in sugars in the treated A-PHL. This result can be attributed to the fact that the higher flow rate might cause the solution (A-PHL) to pass through with a shorter retention time in the resin column, resulting in insufficient time for the PS-DVB resin to adsorb the fermentation inhibitors. This phenomenon is in agreement with the work of Lin et al. (2017) [39], who found that a higher resin feed flow rate could result in a higher Reynolds number and prolong the mass transfer zone, leading to a shorter breakthrough time and then decreasing the diffusion coefficient of the resin for the adsorption of substances in aqueous solution. Based on the best fermentation inhibitor removal performance of PS-DVB with the highest retention of xylose for subsequent fermentation, a feed flow rate of $2 \mathrm{~mL} / \mathrm{min}$ was chosen as the optimal condition for the use of the resin.

As shown in Table 1, the concentration of soluble lignin, HMF, and furfural in PS-DVB treated A-PHL (P-A-PHL) were $1.1 \mathrm{~g} / \mathrm{L}, 0.04 \mathrm{~g} / \mathrm{L}$, and $0.61 \mathrm{~g} / \mathrm{L}$, respectively. Each of these quantified values is significantly lower than that in the original A-PHL solution $(46.9 \mathrm{~g} / \mathrm{L}, 1.9 \mathrm{~g} / \mathrm{L}$, and $7.8 \mathrm{~g} / \mathrm{L}$, respectively). These results indicate that not only can $97 \%$ of the lignin be removed, but also $92-97 \%$ of sugars byproducts can be separated from the xylose solution. In addition, a high r proportion (96\%) of xylose was retained in P-A-PHL. These results indicate that this process can simultaneously separate and recover lignin and sugars in PHL with recovery $>90 \%$, which is more effective than the 
reported technologies of acidification, nanofiltration or microfiltration, applying cationic polymers (e.g., p-DADMAC), activated carbon, or lime mud $[1,19,25]$. Overall, the low concentration of fermentation inhibitors in P-A-PHL suggests that the fermentability of A-PHL should be sufficient for producing ethanol and XA, which will be verified in the subsequent work.

To further understand the structural changes of the carbohydrates and lignin in A-PHL after being treated by PS-DVB resin, 2D-HSQC spectra of A-PHL and P-A-PHL were obtained and are shown in Fig. 1b and Fig. 1c, respectively. A-PHL showed the similar cross-signals for various substructures of lignin and carbohydrate in the 2D-HSQC spectra compared to those in the original PHL spectra (Fig. 1a). However, the signal intensities of $\beta-0-4$ substructures in the A-PHL spectra were significantly lower than those in the PHL spectra. This difference might be due to the cleavage of ether bond under the acidic hydrothermal conditions of acid hydrolysis [40]. For the 2D-HSQC spectra of P-A-PHL, the signals observed for carbohydrates remained in similar positions compared to those noted in the A-PHL spectra (Fig. 1c). Importantly, the correlations of lignin substructures and units were absent in the P-A-PHL spectra. This result again indicates the successful removal of lignin from A-PHL, which is attributed to the adsorption ability of PS-DVB resin.

\section{Fermentation of A-PHL and P-A-PHL by Pichia stipites (P. stipitis) to produce ethanol}

To understand the improvement in the fermentability of A-PHL after being treated by PS-DVB resin, both A-PHL and P-A-PHL (containing the same xylose concentration of $30 \mathrm{~g} / \mathrm{L}$ and $50 \mathrm{~g} / \mathrm{L}$ ) were used as the fermentation stocks to produce ethanol by Pichia stipites (P. stipitis) yeast. The concentration of xylose was selected based on the general tolerance ability of $P$. stipitis for xylose. The fermentation inhibitor concentrations in prepared A-PHL and P-A-PHL containing different xylose concentrations are listed in Table 2. The xylose consumption and ethanol production of A-PHL and P-A-PHL are shown in Fig. $\mathbf{4 a}$ and Fig. $\mathbf{4 b}$, respectively. The ethanol yields, which are defined as the percentage of the total amount of ethanol that could be produced from consumed xylose, are shown in Fig. 4c.

Table 2 Composition analysis of prepared A-PHL and P-A-PHL containing different xylose concentrations ( $\mathrm{g} / \mathrm{L}$ ) for ethanol and xylosic acid fermentation

\begin{tabular}{lllllllllll}
\hline \multicolumn{9}{c}{ A-PHL $^{\text {a }}$} & \multicolumn{5}{c}{ P-A-PHL $^{\text {a }}$} \\
\hline Xylose & $30.1 \pm 0.1$ & $40.2 \pm 0.3$ & $50.3 \pm 0.1$ & $90.5 \pm 0.2$ & $150.6 \pm 1.1$ & $30.3 \pm 0.3$ & $40.6 \pm 0.1$ & $50.3 \pm 0.9$ & $90.9 \pm 0.3$ & $150 \pm 0.1$ \\
HMF & $0.6 \pm 0.5$ & $0.8 \pm 0.4$ & $0.8 \pm 0.1$ & $1.8 \pm 0.4$ & $2.8 \pm 0.3$ & $0 \pm 0.0$ & $0 \pm 0.0$ & $0 \pm 0.0$ & $0.1 \pm 0.0$ & $0.1 \pm 0.0$ \\
Furfural & $2.4 \pm 0.2$ & $3.2 \pm 0.3$ & $3.9 \pm 0.7$ & $6.7 \pm 1.2$ & $10.8 \pm 0.9$ & $0.2 \pm 0.5$ & $0.3 \pm 0.1$ & $0.3 \pm 1.1$ & $0.6 \pm 0.4$ & $1.2 \pm 1.3$ \\
$\begin{array}{l}\text { Soluble } \\
\text { lignin }\end{array}$ & $15.4 \pm 1.3$ & $20.1 \pm 0.9$ & $23.5 \pm 0.8$ & $41.3 \pm 0.7$ & $59.9 \pm 1.2$ & $0.8 \pm 1.1$ & $0.9 \pm 0.5$ & $1.0 \pm 0.2$ & $2.3 \pm 0.4$ & $3.0 \pm 1.4$ \\
\hline
\end{tabular}

a: prepared from corresponding solutions by dilution or concentration

The results in Fig. 4a revealed that A-PHL has low ethanol fermentation productivity with $P$. stipitis. Specifically, xylose in A-PHL was slowly consumed during the fermentation process. After $36 \mathrm{~h}$ of fermentation , $20.2 \mathrm{~g} / \mathrm{L}$ and $41.6 \mathrm{~g} / \mathrm{L}$ of xylose remained in A-PHL with initial xylose concentrations of $30 \mathrm{~g} / \mathrm{L}$ and $50 \mathrm{~g} / \mathrm{L}$, indicated that only $32.6 \%$ and $16.8 \%$ of xylose in A-PHL were consumed, respectively. The ethanol yield (Fig. 4c) obtained from A-PHL containing $50 \mathrm{~g} / \mathrm{L}$ xylose was only $12.0 \%$, which was lower than that of A-PHL containing $30 \mathrm{~g} / \mathrm{L}$ xylose (23.5\%). The low fermentability of A-PHL for producing the ethanol by P. stipitis was therefore due to its high concentration of inhibitors [41, 42]. A total of $0.57 \mathrm{~g} / \mathrm{L} \mathrm{HMF}$ and $2.36 \mathrm{~g} / \mathrm{L}$ furfural were present in A-PHL containing $30 \mathrm{~g} / \mathrm{L}$ xylose and $0.82 \mathrm{~g} / \mathrm{L}$ HMF and $3.93 \mathrm{~g} / \mathrm{L}$ furfural were present in A-PHL containing $50 \mathrm{~g} / \mathrm{L}$ xylose. As pointed out by Díaz et al. (2009) [41], an inhibitory effect on ethanol fermentation by $P$. stipitis can be observed with furfural concentrations of $1-2 \mathrm{~g} / \mathrm{L}$, and almost no sugars can be consumed when there is greater than $4 \mathrm{~g} / \mathrm{L}$ furfural in the fermentation media.

From Fig. 4b, it can be seen that PS-DVB resin treatment remarkably improved the fermentability of A-PHL for ethanol production. $80 \%$ and $47 \%$ of the xylose in P-A-PHL containing $30 \mathrm{~g} / \mathrm{L}$ xylose and $50 \mathrm{~g} / \mathrm{L}$ xylose was consumed after $36 \mathrm{~h}$ of fermentation, resulting in ethanol yields of $61.8 \%$ and $45.9 \%$, respectively. Compared to the results for untreated A-PHL containing $30 \mathrm{~g} / \mathrm{L}$ and $50 \mathrm{~g} / \mathrm{L}$ xylose, the ethanol yield was improved by $162 \%$ and $282 \%$, respectively. The improved fermentability of P-A-PHL therefore must be due to the removal of fermentation inhibitors (HMF, furfural, and soluble lignin). As shown in Table 3, the concentrations of HMF, furfural, and soluble lignin in P-A-PHL containing $30 \mathrm{~g} / \mathrm{L}$ and $50 \mathrm{~g} / \mathrm{L}$ xylose were $0 \mathrm{~g} / \mathrm{L}, 0.21-0.30 \mathrm{~g} / \mathrm{L}$, and 0.75-1.01 g/L, respectively, which were significantly lower than those in untreated A-PHL. In view of the other technologies that have been used to improve the fermentability of 
sugar solutions with inhibitors, Lai et al., (2016) [42] reported that the ethanol production could be increased by $45.5 \%$ and $42.8 \%$ for the prehydrolyzate treated with cetyltrimethylammonium- and benzyltrimethylammonium-modified bentonites, respectively. Zhu et al., (2011) [43] reported that a trialkylamine extraction technology could be used remove $45.7 \% \mathrm{HMF}$ and $100 \%$ furfural from prehydrolyzate, which could improve its fermentability by $P$. stipitis by a degree of $89.6 \%$. Based on the aforementioned results, it can be concluded that PS-DVB resin treatment is a valid detoxification method to improve A-PHL fermentability for ethanol production.

According to the results in Fig. 4 c, the fermentability of A-PHL and P-A-PHL containing $50 \mathrm{~g} / \mathrm{L}$ xylose was weaker than that of A-PHL and P-A-PHL containing $30 \mathrm{~g} / \mathrm{L}$ xylose. Two reasons can explain this phenomenon. First, the concentrations of furfural and soluble lignin in A-PHL containing $50 \mathrm{~g} / \mathrm{L}$ xylose were $3.9 \mathrm{~g} / \mathrm{L}$ and $0.3 \mathrm{~g} / \mathrm{L}$, and those in P-A-PHL containing $50 \mathrm{~g} / \mathrm{L}$ xylose were $23.5 \mathrm{~g} / \mathrm{L}$ and $1.0 \mathrm{~g} / \mathrm{L}$, respectively; these values were higher than those in A-PHL and P-A-PHL containing $30 \mathrm{~g} / \mathrm{L}$ xylose. The higher concentrations of these fermentation inhibitors may show greater inhibition of the bioconversion ability of $P$. stipitis to produce ethanol [37]. Second, A-PHL and P-A-PHL containing a higher xylose concentration $(50 \mathrm{~g} / \mathrm{L})$ may inhibit the bioconversion ability of $P$. stipitis. As pointed out by Agbogbo and Coward-Kelly (2008) [44], ethanol productivity can be inhibited when the initial xylose concentration is $50 \mathrm{~g} / \mathrm{L}$, which is called sugar inhibition.

\section{Fermentation of A-PHL and P-A-PHL for producing XA by Gluconobacter oxydans (G. oxydans)}

The fermentability of A-PHL treated by PS-DVB resin with different xylose concentrations (40,90, and $150 \mathrm{~g} / \mathrm{L})$ to produce XA by Gluconobacter oxydans (G. oxydans) were investigated. As shown in Fig.5a, the xylose in A-PHL containing $40 \mathrm{~g} / \mathrm{L}$ xylose could be completely consumed within $48 \mathrm{~h}$, resulting in an XA production of $44.4 \mathrm{~g} / \mathrm{L}$ and a corresponding yield of $96.6 \%$ (Fig.5c). When increasing the A-PHL xylose concentration to $90 \mathrm{~g} / \mathrm{L}$, even a better XA production of $58.8 \mathrm{~g} / \mathrm{L}$ could be achieved at $48 \mathrm{~h}$. However, only $49.7 \%$ of the xylose was consumed by G. oxydans to produce XA, with a yield of $60.6 \%$. When further increasing the A-PHL xylose concentration to $150 \mathrm{~g} / \mathrm{L}$, only $12.1 \%$ of the xylose could be consumed to produce $\mathrm{XA}$, with a yield of $12.1 \%(4.7 \mathrm{~g} / \mathrm{L})$ at $48 \mathrm{~h}$. From these results, it can be seen that the bioconversion of xylose in A-PHL was strongly inhibited by increases in the concentration of xylose from 40-150 g/L, which can be attributed to the corresponding increased concentration of furfural in A-PHL. As can be seen in Table 2, A-PHL containing $40 \mathrm{~g} / \mathrm{L}$ and $90 \mathrm{~g} / \mathrm{L}$ xylose contained $3.2 \mathrm{~g} / \mathrm{L}$ and $6.7 \mathrm{~g} / \mathrm{L}$ furfural, which were the values within the tolerance of $G$. oxydans to produce XA. However, there was $10.8 \mathrm{~g} / \mathrm{L}$ of furfural in A-PHL containing $150 \mathrm{~g} / \mathrm{L}$ xylose, which is beyond the tolerance threshold for bioconversion. As pointed out by Zhou et al., (2018) [37], the bioconversion ability of $G$. oxydans can be reduced by $60 \%$ when the furfural concentration in fermentation media is increased from $\sim 10$ to $15 \mathrm{~g} / \mathrm{L}$.

Since high concentration of furfural causes severe inhibition of the bioconversion ability of $G$. oxydans [45], we also use the PS-DVB resin to treat A-PHL to produce XA by G. oxydans. As seen in Fig.5b, predictably enhanced XA productivity with $71.6 \%$ and $26.1 \%$ yields was achieved with P-A-PHL containing $90 \mathrm{~g} / \mathrm{L}$ and $150 \mathrm{~g} / \mathrm{L}$ xylose, corresponding to improvements of $18 \%$ and $828 \%$ compared to the yields of A-PHL containing $90 \mathrm{~g} / \mathrm{L}$ and $150 \mathrm{~g} / \mathrm{L}$ xylose, respectively. The tremendous improvement obtained with A-PHL was due to its low concentration of furfural, which was achieved by PS-DVB treatment. According to the research of Chai et al.(2013) [46], the inhibition by furfural towards whole-cell catalysis of $G$. oxydans can be avoided by implementation by furfural removal. Our observations support this previous finding. Overall, it can be concluded that PS-DVB resin treatment is also a potential detoxification method for A-PHL to improve its fermentability for XA production, especially when using PHL with high concentrations of xylose and fermentation inhibitors.

\section{Prospect of the protocol for industry application}

In the kraft-based dissolving pulp industry, prehydrolysis is a crucial stage that can result in dissolving the majority of the hemicelluloses and part of the lignin in PHL. Currently, PHL is mostly concentrated with the black liquid from the cooking process and burned in the recovery boiler $[4,7]$. Hence, using the generated PHL to produce biobased chemicals means that the cost for the feedstock is almost zero. It is estimated that the global production of dissolving pulp was 5.6 million tons in 2013 and 7.5 million tons in 2015; these quantities can produce 50-80 million tons $\mathrm{PHL}$ (nonconcentrated) $[47,48]$. The large amount of PHL produced will provide adequate feedstock for the industrial-scale production of ethanol and XA by the current protocol. Acid hydrolysis is a mature and commercial technology for the production of platform chemicals, such as furfural and HMF [49]. In this work, this technology has also been proposed to enrich the xylose amount in PHL to prepare a fermentation substrate. Acid hydrolysis was carried out and optimized at a $4 \%$ sulfuric acid dosage at $100^{\circ} \mathrm{C}$ for $80 \mathrm{~min}$. These low conditions for preparing the fermentation feedstock indicate that this treatment may result in less reactor corrosion and lower costs for investment, operation, and management [50]. After treatment with PS-DVB, the bioconversion efficiency reached $61.8 \%$ for ethanol production from feedstock containing $30 \mathrm{~g} / \mathrm{L}$ xylose and $96.6 \%$ for XA production from feedstock containing $40 \mathrm{~g} / \mathrm{L}$ xylose. Regarding the final products ethanol and XA, both are important industrial products that can be applied in different areas $[11,13,14]$. Importantly, the used resin can be reused by regenerating it with ethanol, which can be obtained 
from self-production in the current protocol. Regarding reuse, it can be seen that (Table S2) after different 5 cycle times, the resin could still remove HFM, furfural and soluble lignin, with reuse efficiencies of $97.9-99.3 \%, 91.5-90.2 \%$, and $94.2-95.1 \%$, respectively. In addition, the recovery yield of xylose was still over $94 \%$ after 5 cycles. The good reuse efficiency of regenerated resin indicated that it has a long lifetime and satisfactory regeneration ability for processing, suggesting potential applications in industry. The adsorbed substances (HFM, furfural and soluble lignin) in the resin can be recovered after being desorbed by ethanol. Due to differences in molecular weight and boiling point, the HFM, furfural and soluble lignin in desorbed ethanol can be further separated by distillation, membrane separation, or other combined technologies. All of these products are important platform chemicals that can be further used to synthesize resins, plastics, and other value-added products $[10,51]$

Hence, the potential value-added products produced from A-PHL in the current protocol, such as ethanol, XA, HFM, furfural and lignin, can ideally provide additional revenue streams for dissolving pulp production mills, enhancing their competitiveness [51]. The technology discussed in this work represents a good starting point for future industrial exploitation of PHL due to the low cost of the feedstock, mature technologies, high bioconversion efficiency, satisfactory regeneration of resin, and multiple value-added products. Further research should be carried out to assess industrial applications of this protocol, such as case studies of specific PHLs from different mills, detailed process design, and economic analysis considering costs and revenues.

\section{Conclusion}

Acid hydrolysis was used to treat PHL to enrich its xylose concentration, which was improved from $86.3 \mathrm{~g} / \mathrm{L}$ to $101.1 \mathrm{~g} / \mathrm{L}$ with $4 \%$ sulfuric acid at $100^{\circ} \mathrm{C}$ for $80 \mathrm{~min}$. However, the concentrations of the fermentation inhibitors of HMF and furfural inevitably increased to $1.9 \mathrm{~g} / \mathrm{L}$ and $7.8 \mathrm{~g} / \mathrm{L}$ in A-PHL, respectively. Using PS-DVB resin under optimal condition was found to be an effective adsorptive medium capable of simultaneously removing over $90 \%$ of fermentation inhibitors while retaining over $95 \%$ of monosaccharides. After PS-DVB treatment, the ethanol production yield of A-PHL containing $30 \mathrm{~g} / \mathrm{L}$ and $50 \mathrm{~g} / \mathrm{L}$ xylose could be improved by $162 \%$ and $282 \%$, respectively. A similarly elevated productivity of $18 \%$ and $828 \%$ could be achieved for XA production from the same treated A-PHL containing containing $90 \mathrm{~g} / \mathrm{L}$ and $150 \mathrm{~g} / \mathrm{L}$ xylose, respectively. Overall, this work suggests that PS-DVB resin can be regarded as a sustainable technology to improve the bioconversion of prehydrolysis liquor due to its good performance in removing fermentation inhibitors and high reuse efficiency.

\section{Methods}

\section{Materials}

PHL from mixed hardwood, was kindly provided by Sun Paper Co., Ltd (Shandong Province, China). Pichia stipites (P. stipitis) yeast and Gluconobacter oxydans (G. oxydans) were provided by the Biochemical Engineering Research Institute of Nanjing Forestry University. Amberlite ${ }^{\circledR}$ PS-DVB resin (20-60 mesh, $800 \mathrm{~m}^{2} / \mathrm{g}$ ) was provided by Dow Chemical Company, USA. Analytical grades of furfural ( $\left.>99 \%\right)$, HMF $(>99 \%)$, glucose $(>99 \%)$, xylose $(>99 \%)$, xylosic acid $(>99 \%)$, and yeast extract were obtained from Sigma-Aldrich. Sulfuric acid, sodium hydroxide, anhydrous ethanol, $\mathrm{MgSO}_{4}, \mathrm{KH}_{2} \mathrm{PO}_{4}, \mathrm{CaCl}_{2}, \mathrm{~K}_{2} \mathrm{HPO}_{4}$, and $\left(\mathrm{NH}_{4}\right)_{2} \mathrm{SO}_{4}$ were purchased from Nanhua Chemical Reagent Factory, China. All chemical reagents were purchased from the suppliers and used without purification.

\section{Acid hydrolysis of PHL}

Acid hydrolysis was carried out under different conditions to hydrolyze the xylooligosaccharide into xylose to enrich its amount in PHL. Specifically, a certain amount of concentrated sulfuric acid $(98 \%, w / v)$ was added to PHL to final acid concentrations of $1-5 \%(w / v)$. Acid hydrolysis was carried out in $100 \mathrm{~mL}$ autoclave bombs at $90-130{ }^{\circ} \mathrm{C}$ for $20-100 \mathrm{~min}$. After acid hydrolysis, an aliquot was withdrawn for xylose analysis.

\section{Inhibitors adsorption by PS-DVB resin}

Hydrophobic PS-DVB resin was used to remove soluble lignin, furfural, and HMF from PHL. Specifically, resin particles were sealed inside of a Chromafex glass column $(40 \times 2 \mathrm{~cm})$ and then sequentially washed with water, ethanol, and water to remove the preservative salts, adsorbed impurities, and ethanol, respectively. Next, $500 \mathrm{~mL}$ of the acid-hydrolyzed PHL (A-PHL) was passed through the resin column by the with a pump at different flow rates $(0.5-4 \mathrm{~mL} / \mathrm{min})$. The optimal flow rate was chosen based on the resin's ability to remove fermentation inhibitors. The other conditions were selected according to the work in Narron et al [27]. The permeated solution (purified A$\mathrm{PHL}$ ) was collected and termed P-A-PHL. After elution of P-A-PHL, $500 \mathrm{~mL}$ of deionized water was passed through to collect any soluble 
sugars that remained unadsorbed within the column. Next, $1.5 \mathrm{~L}$ of anhydrous ethanol was eluted through the column to desorb the adsorbates. A final water wash was applied to remove ethanol prior to recovery and reuse of the resin. The efficiency of reused resin was evaluated by adsorbing the fermentation inhibitors in A-PHL for 5 cycle.

\section{Fermentation of PHL into ethanol}

P. stipitis was used to ferment xylose into ethanol. To activate and inoculate the $P$. stipitis, the yeast was loaded into seed culture solution containing $20 \mathrm{~g} / \mathrm{L}$ xylose, $3 \mathrm{~g} / \mathrm{L}$ peptone, and $5 \mathrm{~g} / \mathrm{L}$ yeast extract and cultured for $72 \mathrm{~h}$ at $30^{\circ} \mathrm{C}$ under shaking at $150 \mathrm{rpm}$. Once the density of the yeast reached $15 \mathrm{~g} / \mathrm{L}$ (cell dry weight), the yeast cells were harvested by centrifugation and then inoculated into the fermentation media, which contained $0.08 \mathrm{~g} / \mathrm{L} \mathrm{MgSO}_{4}, 2.5 \mathrm{~g} / \mathrm{L} \mathrm{KH}_{2} \mathrm{PO}_{4}, 0.25 \mathrm{~g} / \mathrm{L} \mathrm{CaCl}{ }_{2}, 0.24 \mathrm{~g} / \mathrm{L}$ urea and P-A-PHL solutions containing $30 \mathrm{~g} / \mathrm{L}$ and $50 \mathrm{~g} / \mathrm{L}$ xylose. The $\mathrm{pH}$ of fermentation medias were controlled at 6.0 . Xylose fermentation was carried out at at $30^{\circ} \mathrm{C}$ with $150 \mathrm{rpm}$ shaking for $36 \mathrm{~h}$. To evaluate the difference in the fermentability difference of A-PHL after purification, A-PHL samples with the same concentrations were also fermented under the same conditions. All fermentations were carried out in a 250-mL Erlenmeyer flask with a working volume of $50 \mathrm{~mL}$. Fermentation was performed with no oxygen supply, but the flasks were not strictly anaerobic due to the use of cotton-wool plugs as seals for the flasks [52]. During fermentation, an aliquot was withdrawn for xylose and ethanol analysis at regular intervals on a sterile workbench. Ethanol yield was calculated according to the following equation:

Ethanol yield $(\%)=\frac{\text { Produced } \text { ethanol }(\mathrm{g})}{\text { Consumed } x y l o s e \times 0.46(\mathrm{~g})} \times 100 \%$

\section{Whole-cell catalysis of PHL into xylonic acid}

G. oxydans NL71 was used to ferment xylose into XA by whole-cell catalysis. To activate and inoculate $G$. oxydans, the bacterium was loaded into a seed culture solution containing $80 \mathrm{~g} / \mathrm{L}$ of sorbitol and $8 \mathrm{~g} / \mathrm{L}$ of yeast extract and cultured at $30{ }^{\circ} \mathrm{C}$ under shaking at 220 $\mathrm{rpm}$ for $24 \mathrm{~h}$. Once the cell density reached $4 \mathrm{~g} / \mathrm{L}$ (cell dry weight), cells were harvested by centrifugation and then inoculated into the fermentation media. This fermentation media contained $5 \mathrm{~g} / \mathrm{L} \mathrm{MgSO}_{4}, 0.5 \mathrm{~g} / \mathrm{L} \mathrm{KH}_{2} \mathrm{PO}_{4}, 2 \mathrm{~g} / \mathrm{L} \mathrm{K}_{2} \mathrm{HPO}_{4}, 5 \mathrm{~g} / \mathrm{L}\left(\mathrm{NH}_{4}\right)_{2} \mathrm{SO}_{4}, 5 \mathrm{~g} / \mathrm{L}$ yeast extract and P-A-PHL solutions containing $40 \mathrm{~g} / \mathrm{L}, 90 \mathrm{~g} / \mathrm{L}$ and $150 \mathrm{~g} / \mathrm{L}$ xylose. The $\mathrm{pH}$ of fermentation medias were controlled at $5.0 \mathrm{To}$ evaluate the fermentability difference of A-PHL after purification, A-PHL with the same concentrations were also fermented at the same conditions. Whole-cell catalysis of A-PHL and P-A-PHL solutions were carried out at $30^{\circ} \mathrm{C}$ with $220 \mathrm{rpm}$ shaking for $48 \mathrm{~h}$. All fermentations were carried out in a 250-mL flask with baffles and a working volume of $50 \mathrm{~mL}$. The fermentation flasks were sealed with Parafilm with $0.22 \mu \mathrm{m}$ pores to allow sterile air into the flask for $G$. oxydans fermentation [53]. During fermentation, an aliquot was withdrawn for xylose and XA analysis at regular intervals on a sterile workbench. XA yield was calculated according to the following equation:

$$
\mathrm{XA} \text { yield }(\%)=\frac{\text { Produced } \mathrm{XA}(\mathrm{g})}{\text { Consumed } x y l o s e \times 1.1(\mathrm{~g})} \times 100 \%
$$

\section{Analytical methods}

Monosaccharide (glucose and xylose), ethanol, and fermentation inhibitor (furfural and HMF) concentrations were detected by high performance liquid chromatography (HPLC) system consisting of an Aminex HPX-87H column with $50 \mathrm{mM} \mathrm{H}_{2} \mathrm{SO}_{4}$ as the eluent at a flow rate of $0.6 \mathrm{~mL} / \mathrm{min}[54]$.

The concentration of oligosaccharides in PHL was determined by back calculation using the xylose concentrations before and after acid hydrolysis. Specifically, an aliquot of hydrolyzate was mixed with sulfuric acid to reach a $4 \%$ acid concentration and hydrolyzed at 121 ${ }^{\circ} \mathrm{C}$ for $60 \mathrm{~min}$. The concentration of oligosaccharides was calculated from the differences in the respective monosaccharide contents before and after acid hydrolysis, which were also detected using the above HPLC system.

The concentration of XA was determined by a high performance anion-exchange chromatography (HPAEC) system using a CarboPacTM PA10 column and $\mathrm{NaOH}$ and sodium acetate as eluents at a flow rate of $0.3 \mathrm{~mL} / \mathrm{min}$. The separation method to analyze the XA 
concentrations in HPAEC was performed according to the work of Zhou and Xu (2019) [55].

The concentrations of soluble lignin in $\mathrm{PHL}, \mathrm{A}-\mathrm{PHL}$, and P-A-PHL were determined by using the Lambert-Beer law ( $\left.\mathrm{A}=\bigotimes_{\mathrm{bc}}\right)$, in which the absorbance was obtained from UV spectrophotometry at $280 \mathrm{~nm}$. To avoid lignin overestimation due to furfural and HMF, which also exhibit UV absorption at similar absorption wavelengths as lignin ( $\lambda=280 \mathrm{~nm}), \mathrm{PHL}, \mathrm{A}-\mathrm{PHL}$, and P-A-PHL were subjected to borohydride reduction to render UV-silent furfuryl alcohols according to the work of Narron et al. (2017) [27] and Chi et al. (2009) [56]. The borohydride-treated solutions were used to determine the lignin amount based on UV spectrophotometry.

The chemical structures of PHL, A-PHL, and P-A-PHL were recorded by 2D-HSQC on a Bruker AVIII $600 \mathrm{MHz}$ spectrometer. 50 mg of dried material was dissolved in $0.5 \mathrm{~mL}$ DMSO- $d_{6}$ to obtain 2D-HSQC spectra according to our previous work [32].

\section{Statistical analysis}

All data were examined in three replications and presented as means \pm STD $(n=3)$. Statistical analysis was performed using the oneway analysis of variance (ANOVA) using SPSS statistical software (2008).

\section{Abbreviations}

PHL: pre-hydrolysis liquor; PS-DVB: polystyrene divinylbenzene; A-PHL: acid-hydrolyzed PHL; P-A-PHL: PS-DVB treated A-PHL; XA: xylosic acid; HMF: hydroxymethylfurfural; p-DADMAC: polydiallyldimethylammonium chloride; CPAM: cationic polyacrylamide; two-dimensional heteronuclear single-quantum coherence: 2D-HSQC; NMR: nuclear magnetic resonance; HPLC: high performance liquid chromatography; HPAEC: high performance anion-exchange chromatography; NREL: National Renewable Energy Laboratory; PNNL: Pacific Northwest National Laboratory;

\section{Declarations}

\section{Acknowledgements}

The authors thank Pro. Yong Xu and Dr. Xin Zhou in Nanjing Forestry University for providing the technologies to do XA fermentation assays.

\section{Authors' contributions}

$\mathrm{CH}$ developed the idea for the study, performed the research, data analysis and prepared the manuscript. WL and YS performed the research and data analysis. YZ helped to prepare the PS-DVB resin. QY and GH revised the manuscript. All authors read and approved the final manuscript.

\section{Funding}

This work was supported by the National Natural Science Foundation of China (31800501) and Natural Science Foundation of Jiangsu Province (BK20180772).

\section{Ethics approval and consent to participate}

Not applicable.

\section{Consent for publication}

Not applicable.

\section{Availability of data and material}

All data generated and analyzed in this study are included in this published article.

\section{Competing interests}

The authors declare that they have no competing interests. 


\section{References}

1. Domínguez-Robles J, del Valle Palenzuela M, Sánchez R, Loaiza, JM, Espinosa, E, Rosal A., Rodríguez A. Coagulation-flocculation as an alternative way to reduce the toxicity of the black liquor from the paper industry: thermal valorization of the solid biomass recovered. Waste Biomass Valori. 2019;1-12.

2. Wang Z, Jiang J, Wang X, Fu Y, Li Z, Zhang F, Qin M. Selective removal of phenolic lignin derivatives enables sugars recovery from wood prehydrolysis liquor with remarkable yield. Technol. 2014;174:198-203.

3. Shi H, Fatehi P, Xiao H, Ni Y. Optimizing the poly ethylene oxide flocculation process for isolating lignin of prehydrolysis liquor of a kraft-based dissolving pulp production process. Ind. Eng. Chem. Res. 2012;51(14):5330-5335.

4. Yang G, Jahan M S, Liu H, Ni Y. Acid hydrolysis of prehydrolysis liquor produced from the kraft-based dissolving pulp production process. Ind. Eng. Chem. Res. 2012;51(43):13902-13907.

5. Fatehi P, Catalan L, Cave G. Simulation analysis of producing xylitol from hemicelluloses of pre-hydrolysis liquor. Chemi. Eng. Res. Des. 2014;92(8):1563-70.

6. Adams TN. Kraft recovery boilers. TAPPI press 1997.

7. Farhat W, Venditti RA, Hubbe M, Taha M, Becquart F, Ayoub A. A review of water-resistant hemicellulose-based materials: processing and applications. ChemSusChem 2017;10(2):305-323.

8. Moncada J, Aristizábal V. Design strategies for sustainable biorefineries. Biochem. Eng. J. 2016;116:122-134.

9. Nizami AS, Rehan M, Waqas M, Naqvi M, Ouda OKM., Shahzad K, Pant D. Waste biorefineries: enabling circular economies in developing countries. Bioresour. Technol. 2017;241:1101-1117.

10. Pei W, Shang W, Liang C, Jiang X, Huang C, Yong Q. Using lignin as the precursor to synthesize Fe304@ lignin composite for preparing electromagnetic wave absorbing lignin-phenol-formaldehyde adhesive. Ind. Crop. Prod. 2020;154:112638.

11. Sainio T, Kallioinen M, Nakari O, Mänttäri M. Production and recovery of monosaccharides from lignocellulose hot water extracts in a pulp mill biorefinery. Bioresour. Technol. 2013;135:730-737.

12. Gupta KK, Rehman A, Sarviya RM. Bio-fuels for the gas turbine: A review. Renew. Sust. Energ. Rev. 2010;14(9):2946-2955.

13. Zhou X, Xu Y. Eco-friendly consolidated process for co-production of xylooligosaccharides and fermentable sugars using selfproviding xylonic acid as key pretreatment catalyst. Biotechnol. Biofuels 2019;12(1):1-10.

14. Zhang H, Liu G, Zhang J, Bao J. Fermentative production of high titer gluconic and xylonic acids from corn stover feedstock by Gluconobacter oxydans and techno-economic analysis. Bioresour. Technol. 2016;219:123-131.

15. Lavarack BP, Griffin GJ, Rodman D. The acid hydrolysis of sugarcane bagasse hemicellulose to produce xylose, arabinose, glucose and other products. Biomass Bioenerg. 2002;23(5):367-380.

16. Cao L, Chen H, Tsang DC, Luo G, Hao S, Zhang S, Chen J. Optimizing xylose production from pinewood sawdust through dilutephosphoric-acid hydrolysis by response surface methodology. J. Clean. Prod. 2018;178:572-9.

17. Modenbach AA, Nokes SE. The use of high-solids loadings in biomass pretreatment-a review. Biotechnol. Bioeng. 2012;109(6):14301442 .

18. Jiang X, Narron RH, Han Q, Park S, Chang HM, Jameel H. Tracing Sweetgum Lignin's Molecular Properties through Biorefinery Processing. ChemSusChem. 2020;13(17):4613-4623.

19. Fatehi P, Shen J, Hamdan FC, Ni Y. Improving the adsorption of lignocelluloses of prehydrolysis liquor on precipitated calcium carbonate. Carbohyd. Polym. 2013;92(2):2103-2110.

20. He J, Huang C, Lai C, Huang C, Li X, Yong Q. Elucidation of structure-inhibition relationship of monosaccharides derived pseudolignin in enzymatic hydrolysis. Ind. Crop. Prod. 2018;113:368-375.

21. Goundalkar MJ, Bujanovic B, Amidon TE. Analysis of non-carbohydrate based low-molecular weight organic compounds dissolved during hot-water extraction of sugar maple. Cell. Chem. Technol. 2010;44(1):27.

22. Sun RC. Detoxification and separation of lignocellulosic biomass prior to fermentation for bioethanol production by removal of lignin and hemicelluloses. BioResources 2009;4(2):452-455.

23. Hahn-Hägerdal B, Karhumaa K, Fonseca C, Spencer-Martins I, Gorwa-Grauslund MF. Towards industrial pentose-fermenting yeast strains. App. Microbiol. Biot. 2007;74(5):937-953.

24. Shi H, Fatehi P, Xiao H, Ni Y. A combined acidification/PEO flocculation process to improve the lignin removal from the pre-hydrolysis liquor of kraft-based dissolving pulp production process. Bioresour. Technol. 2011;102(8):5177-5182. 
25. Wang Z, Wang X, Jiang J, Fu Y, Qin M. Fractionation and characterization of saccharides and lignin components in wood prehydrolysis liquor from dissolving pulp production. Carbohyd. Polym. 2015;126:185-191.

26. Yasarla LR, Ramarao BV. Dynamics of flocculation of lignocellulosic hydrolyzates by polymers. Ind. Eng. Chem. Res. 2012;51(19):6847-6861.

27. Narron RH, Chang HM, Jameel H, Park S Soluble lignin recovered from biorefinery pretreatment hydrolyzate characterized by lignincarbohydrate complexes. ACS Sustain. Chem. Eng. 2017;5(11):10763-10771.

28. Huck CW, Bonn GK. Poly (Styrene-Divinylbenzene) Based Media for Liquid Chromatography. Chem. Eng. Technol. 2005;28(12):14571472 .

29. Westerberg N, Sunner H, Gunnar H, Mikaela H, Martin L, Rasmuson A. Separation of galactoglucomannans, lignin and lignincarbohydrate complexes from hot-water-extracted Norway spruce by cross-flow filtration and adsorption chromatography. BioResources. 2012;7:4501-16.

30. Giummarella N, Zhang L, Henriksson G, Lawoko M. Structural features of mildly fractionated lignin carbohydrate complexes (LCC) from spruce. RSC Adv. 2016;6:42120-31.

31. Chen X, Cao X, Sun S, Yuan T, Shi Q, Zheng L, Sun R. Evaluating the production of monosaccharides and xylooligosaccharides from the pre-hydrolysis liquor of kraft pulping process by acid and enzymatic hydrolysis. Ind. Crop. Prod. 2018;124:906-911.

32. Dong H, Zheng L, Yu P, Jiang Q, Wu Y, Huang C, Yin B. Characterization and application of lignin-carbohydrate complexes from lignocellulosic materials as antioxidants for scavenging in vitro and in vivo reactive oxygen species. ACS Sustain. Chem. Eng. 2019;8(1):256-266.

33. Shen XJ, Chen T, Wang HM, Mei Q, Yue F, Sun S, Wen JL, Yuan TQ, Sun RC. Structural and morphological transformations of lignin macromolecules during bio-based deep eutectic solvent (DES) pretreatment. ACS Sustain. Chem. Eng. 2019;8(5):2130-2137.

34. Wang HM, Ma CY, Li HY, Chen TY, Wen JL, Cao XF, Wang XL, Yuan TQ, Sun RC. Structural variations of lignin macromolecules from early growth stages of poplar cell walls. ACS Sustain. Chem. Eng. 2019;8(4):1813-1822.

35. Yang W, Li P, Bo D, Chang H. The optimization of formic acid hydrolysis of xylose in furfural production. Carbohyd. Res. 2012;357:5361.

36. Bellido C, Bolado S, Coca M, Lucas S, González-Benito G, García-Cubero MT. Effect of inhibitors formed during wheat straw pretreatment on ethanol fermentation by Pichia stipitis. Bioresour. Technol. 2011;102(23):10868-10874.

37. Zhou X, Zhou X, Xu Y, Chen RR. Gluconobacter oxydans (ATCC 621H) catalyzed oxidation of furfural for detoxification of furfural and bioproduction of furoic acid. J. Chem. Technol. Biot. 2017;92(6):1285-1289.

38. Wang L, Chen $\mathrm{H}$. Increased fermentability of enzymatically hydrolyzed steam-exploded corn stover for butanol production by removal of fermentation inhibitors. Process Biochem. 2011;46(2):604-607.

39. Lin X, Huang Q, Qi G, Shi S, Xiong L, Huang C, Chen X, Li H, Chen X. Estimation of fixed-bed column parameters and mathematical modeling of breakthrough behaviors for adsorption of levulinic acid from aqueous solution using SY-01 resin. Sep. Purif. Technol. 2017;174:222-31.

40. Chen X, Cao X, Sun S, Yuan T, Wang S, Shi Q, Sun R. Hydrothermal acid hydrolysis for highly efficient separation of lignin and xylose from pre-hydrolysis liquor of kraft pulping process. Sep. Purif. Technol. 2019;209:741-747.

41. Díaz MJ, Ruiz E, Romero I, Cara C, Moya M, Castro E. Inhibition of Pichia stipitis fermentation of hydrolysates from olive tree cuttings. World J. Microb. Biot. 2009;25(5):891-899.

42. Lai C, Li X, Zhu J, Yu S, Yong Q. Detoxification of steam-exploded corn stover prehydrolyzate with organobentonite enhances ethanol fermentation by Pichia stipitis. Bioresources 2016;11(1):1905-1918.

43. Zhu J, Yong Q, Xu Y, Yu S. Detoxification of corn stover prehydrolyzate by trialkylamine extraction to improve the ethanol production with Pichia stipitis CBS 5776. Bioresour. Technol. 2011;102(2):1663-1668.

44. Agbogbo FK, Coward-Kelly G. Cellulosic ethanol production using the naturally occurring xylose-fermenting yeast, Pichia stipitis. Biotechnology letters. 2008;30(9):1515-24.

45. Zhao J, Zhang X, Lei W, Ji X, Zhou X, Xu Y. Mannonic acid and bio-ethanol production from konjac using a two-step bioprocess with Candida shehatae and Gluconobacter oxydans. J Renew. Mater. 2020;8(1): 79.

46. Chai WM, Liu X, Hu YH, Feng HL, Jia YL, Guo YJ, Zhou HT, Chen QX. Antityrosinase and antimicrobial activities of furfuryl alcohol, furfural and furoic acid. Int. J. Biol. Macromol. 2013;57:151-155. 
47. Yang S, Wen Y, Zhang H, Li J, Ni Y. Enhancing the Fock reactivity of dissolving pulp by the combined prerefining and poly dimethyl diallyl ammonium chloride-assisted cellulase treatment.Bioresour. Technol. 2018;260:135-40.

48. Kumar H, Christopher LP. Recent trends and developments in dissolving pulp production and application. Cellulose. 2017;24(6):234765.

49. Bariani M, Boix E, Cassella F, Cabrera MN. Furfural production from rice husks within a biorefinery framework. Biomass Convers. Bior. 2020;20:1-4.

50. Modenbach, A.A., Nokes, S.E., 2012. The use of high-solids loadings in biomass pretreatment-a review. Biotechnol. Bioeng. 109, $1430-1442$.

51. Yang B, Wang B, Wang G, He Z, Ni Y. Integrated Forest Biorefinery: Value-added Utilization of Dissolved Organics in the Prehydrolysis Liquor of Prehydrolysis Kraft (PHK) Dissolving Pulp Production Process. Paper and Biomaterials. $2018 ; 27(3): 7$.

52. Delgenès JP, Moletta R, Navarro JM. Effects of lignocellulose degradation products on ethanol fermentations of glucose and xylose by Saccharomyces cerevisiae, Zymomonas mobilis, Pichia stipitis, and Candida shehatae. Enzyme Microb. Tech. 1996;19(3):220-5.

53. Zhou X, Zhou X, Liu G, Xu Y, Balan V. Integrated production of gluconic acid and xylonic acid using dilute acid pretreated corn stover by two-stage fermentation. Biochemical Engineering Journal. 2018 Sep 15;137:18-22.

54. Lin W, Xing S, Jin Y, Lu X, Huang C, Yong Q Insight into understanding the performance of deep eutectic solvent pretreatment on improving enzymatic digestibility of bamboo residues. Bioresour. Technol. 2020;123163.

55. Zhou X, Xu Y. Integrative process for sugarcane bagasse biorefinery to co-produce xylooligosaccharides and gluconic acid. Bioresour. Technol. 2019;282:81-87.

56. Chi C, Zhang Z, Chang HM, Jameel, H. Determination of furfural and hydroxymethylfurfural formed from biomass under acidic conditions. J. Wood Chem. Technol. 2009;29 (4): 265-276.

\section{Figures}



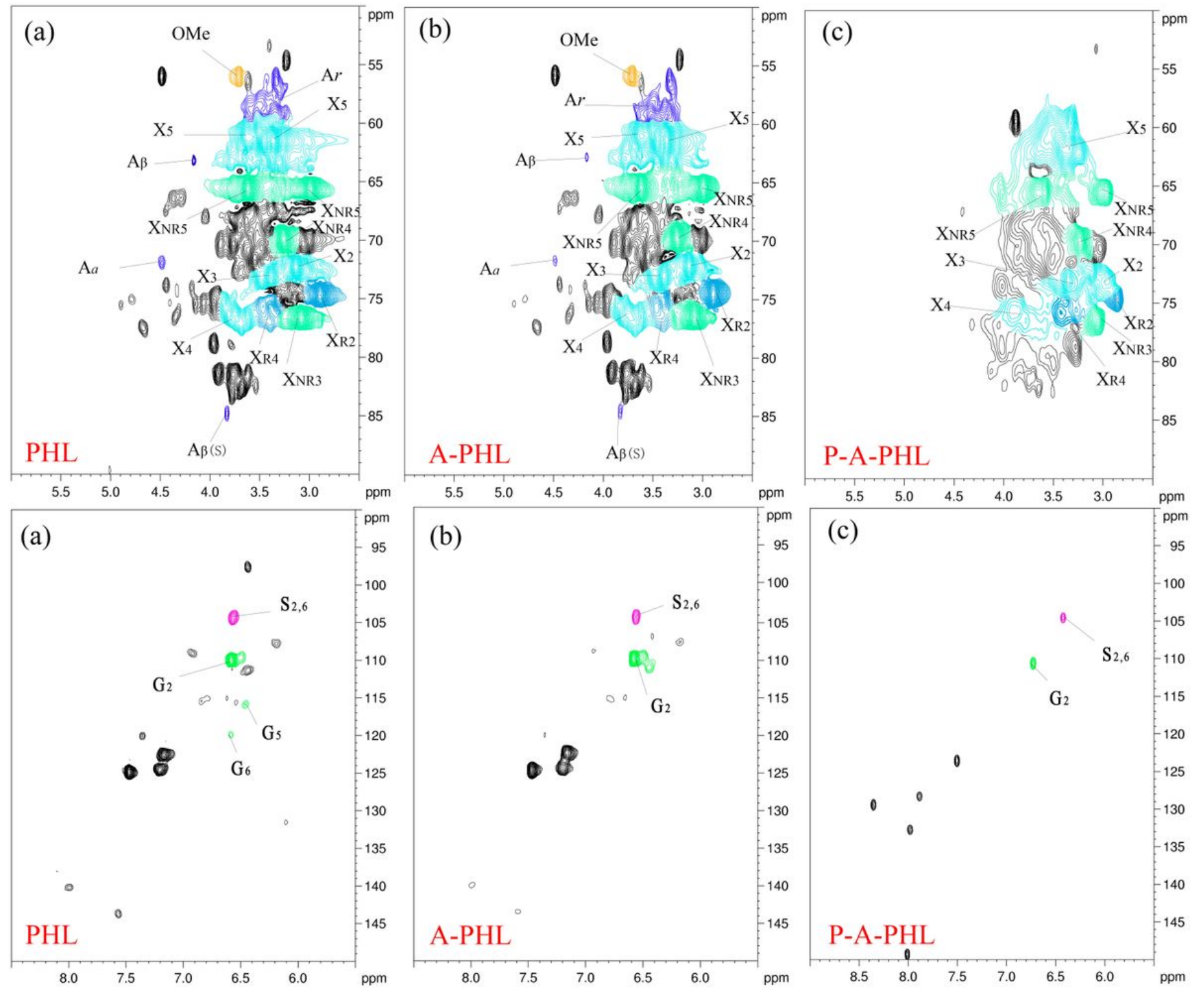

Figure 1

2D-HSQC NMR spectra of PHL (a), A-PHL (b), and P-A-PHL (c) 


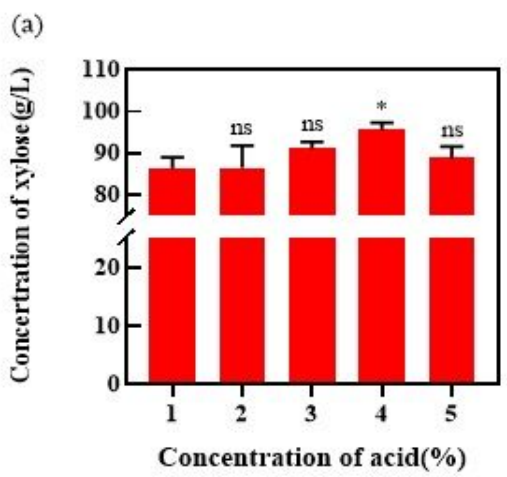

(b)

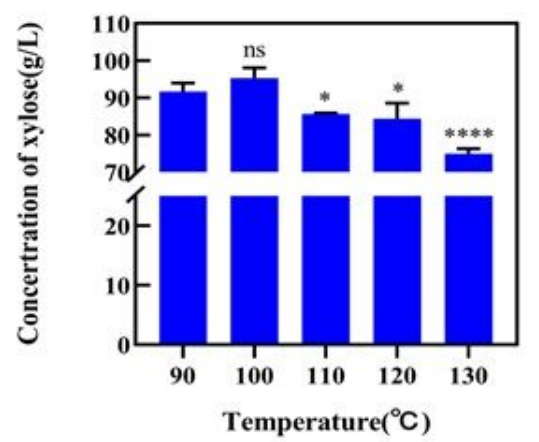

(c)

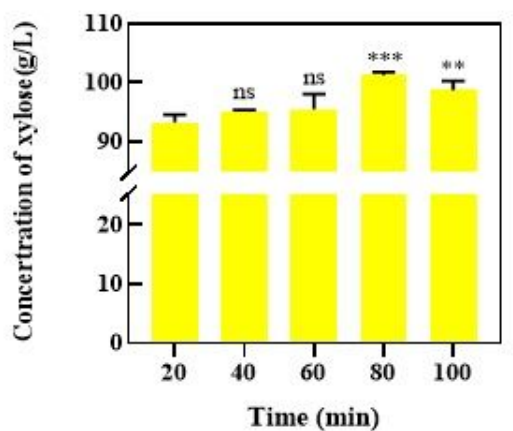

\section{Figure 2}

Effects of the acid concentration (a), temperature (b), and reaction time (c) of acid hydrolysis on xylose production ((a: temperature: 100 ${ }^{\circ} \mathrm{C}$; time: $\left.60 \mathrm{~min}\right)$, (b: acid concentration: 4\%; time: $\left.60 \mathrm{~min}\right)$, (c: acid concentration: 4\%; temperature: $\left.100{ }^{\circ} \mathrm{C}\right)$ ); ns denotes no significant

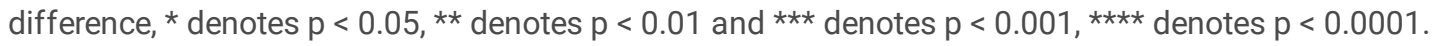




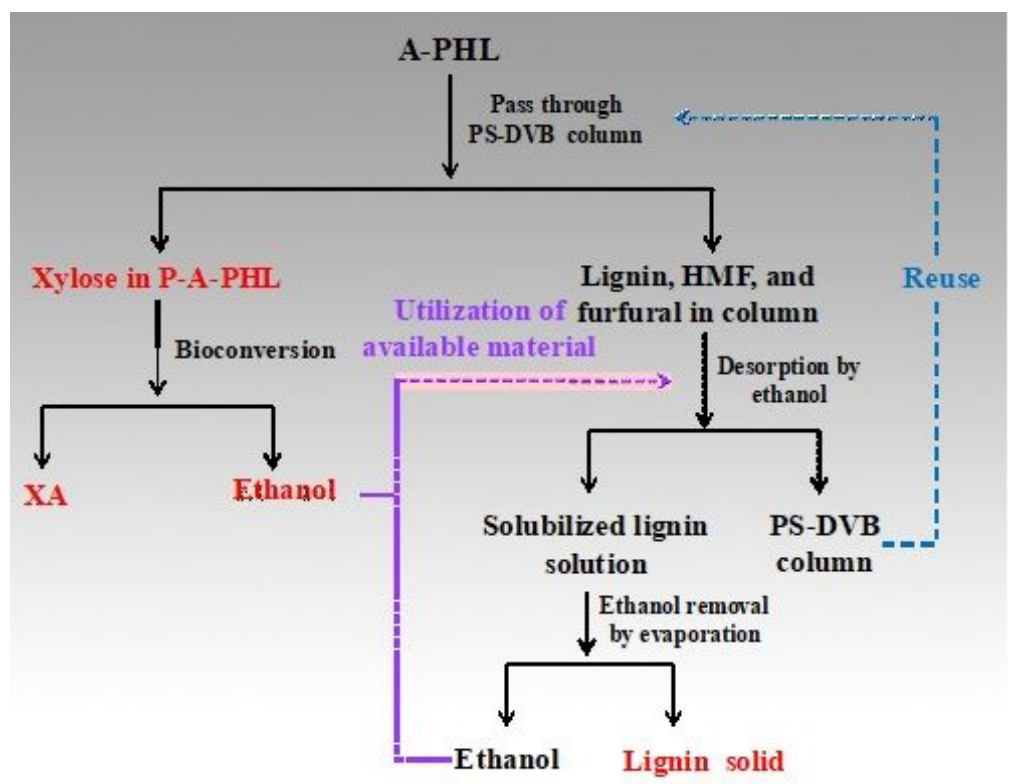

Figure 3

Proposed process diagram for the removal of lignin and sugar byproducts (furfural and HMF) from PHL
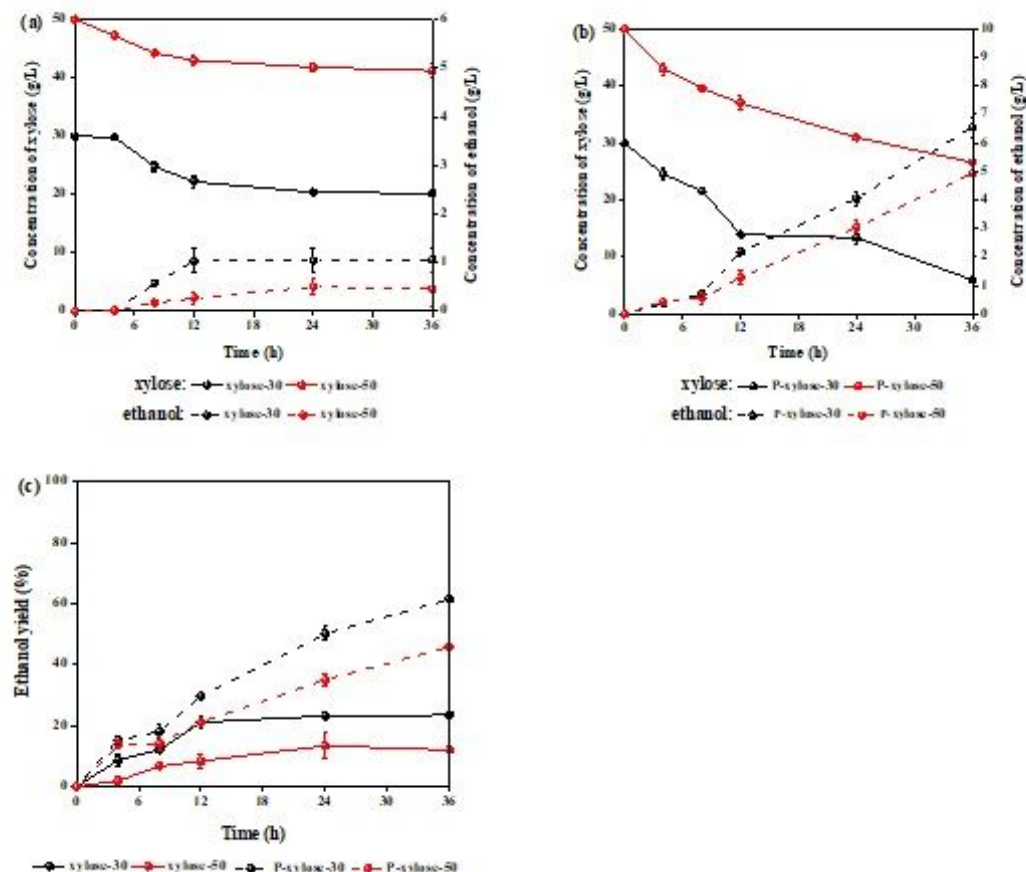

Figure 4

Xylose consumption and ethanol production of A-PHL (a) and P-A-PHL (b), and their ethanol yields (c) 

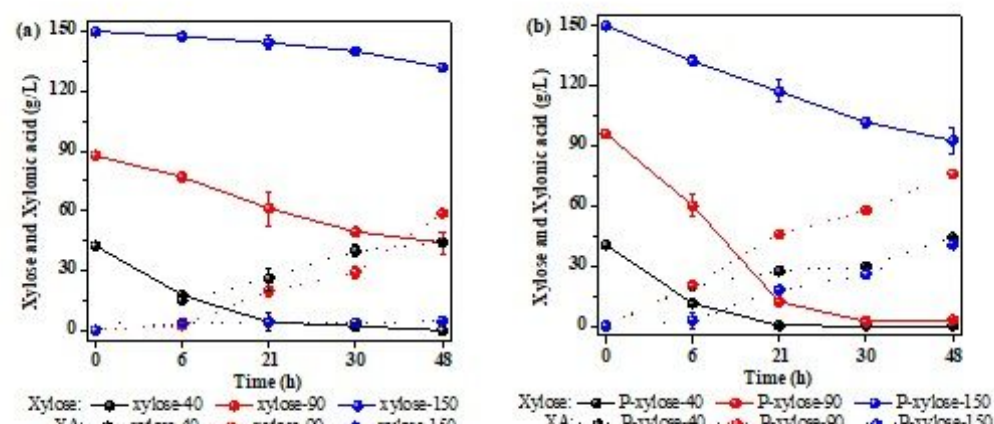

$X A: \cdot x y 105 e-40 \cdot x y 10 \%-90 \cdot x y 106=-150$

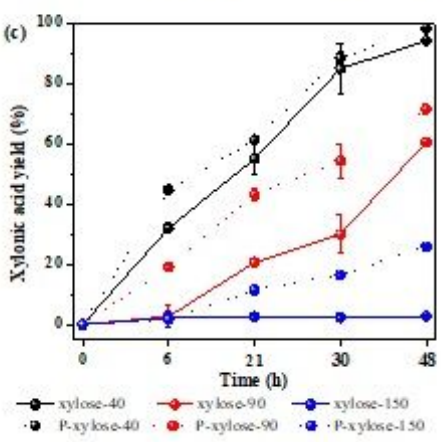

Figure 5

Xylose consumption and XA production of A-PHL (a) and P-A-PHL (b), and their XA yields (c)

\section{Supplementary Files}

This is a list of supplementary files associated with this preprint. Click to download.

- SupplementaryMaterial.pdf 